\title{
Assessment of pesticide residue levels among locally produced fruits and vegetables in Monze district, Zambia
}

\author{
Mildred Mwanja ${ }^{1,2^{*}}$, Choolwe Jacobs ${ }^{3}$, Allan Rabson Mbewe ${ }^{2}$ and Nosiku Sipilanyambe Munyinda ${ }^{2}$
}

\begin{abstract}
Background: The use of pesticides in fruits and vegetable production is beneficial for preventing, destroying or repelling pests that may damage these crops. The use of these chemicals however, often leads to the presence of residues in the fruits and vegetables after harvest. This study investigated farmers' compliance to applicable national standards by assessing pesticide residues in selected locally produced fruits and vegetables in two study sites in Monze, Zambia. The study used mixed methods (convergent parallel) design. We procured rape, cabbages, tomato and orange samples from conveniently sampled fruit and vegetable farmers around Hachaanga and St. Mary's areas in Monze, Zambia. Samples were analyzed for residues of dichlorvos using gas chromatography-mass spectrometry (GC-MS). Estimated average daily intakes (EADI) were calculated using standard formula. We also explored farmers' practices in dealing with regulatory issues in pesticide use and handling. A total of 14 key informant interviews with farmers, agriculture and public health officers and one policy maker were undertaken using a semi structured interview guide, were voice recorded, later transcribed and analyzed using Nvivo 10 software.

Results: Results revealed detectable residues in $63.3 \%$ of 30 tested samples out of which three samples (one each of cabbage, tomato and orange samples) exceeded the codex Alimentarius maximum residual limit ( $0.1 \mathrm{mg} / \mathrm{kg})$. However, all samples had residues below the Zambia Food and Drugs standard ( $0.5 \mathrm{ppm})$. The EADls were also below WHO/FAO allowable daily intake recommended in all fruit and vegetable samples; however hazard indices for cabbage and oranges were close to the value one. In regard to farmers' practices, results showed great variation in pesticide use and handling, limited knowledge, observation of reduced waiting periods and limited monitoring and regulation of pesticide use among farmers.

Conclusion: Our investigation found that all our samples had residues within the locally applicable regulation limits. All our EADIs were below the FAOMHO limits. However, farmers' practices in pesticide use and handling were not conformity to guidelines. Therefore, there is need for educating food producers on handling and hazards of pesticides in Zambia.
\end{abstract}

Keywords: Pesticide residues, Maximum Residue Limit, Pesticide use and handling, Farmers' practices

\section{Background}

The use of pesticides in agricultural sector in Zambia has increasingly become an important aspect of agricultural technology and innovation, critical for agriculture development, economic growth and poverty reduction (Bwalya 2010). Globally, the use of pesticides in food

\footnotetext{
* Correspondence: mwanjamildred@yahoo.com

${ }^{1}$ Environmental Health Department, Monze District Medical Office, P.O. Box 66144, Monze, Zambia

${ }^{2}$ School of Medicine Department of Public Health, Environmental Health Unit, University of Zambia, P.O Box 50110, Ridgeway, Lusaka, Zambia Full list of author information is available at the end of the article
}

production is common with many famers using commercial pesticides for pest control to increase yield and improve quality. The World Health Organization (WHO) reports that $20 \%$ of pesticide use in the world is concentrated in developing countries (PAN G 2012). Over the past couple of decades, a rapid increase in the quantity and use of pesticides in the agriculture sector has been observed. This trend is expected to continue for the coming decade due to social, economic and technological developments (Greish et al. 2011). Pests and diseases attack fruits and vegetables from cultivation through to storage. Pesticides are used to preserve their 
quality and prevent diseases. While the use of these chemical pesticides enhances the farmer's productivity, inappropriate pesticide use poses health hazards to consumers, other organisms and the environment (Wang et al. 2010).

Since the banning of organochlorine pesticides, organophosphates including dichlorvos became the most commonly used pesticides despite their World Health Organization classification as "hazardous" (PAN G 2012). Dichlorvos is known to be among pesticides frequently associated with documented cases of poisoning resulting in acute or chronic adverse health effects (Mowry et al. 2015). These pesticides are often applied indiscriminately and inappropriately (Ntow et al. 2006), resulting in adverse environmental and health effects. Several studies that have evaluated pesticide residues in fruits and vegetables revealed that fruits and vegetables may contain remnants of insecticides above the Maximum Residue Limits (MRL) set by the United Nations through the Codex Alimentarius Commission (Farag et al. 2011; Boland et al. 2004).

Good agriculture practices (GAP) in pesticide application can reduce the risk of pesticide contamination to users (Boland et al. 2004). However, farmers require knowledge on the right dosage, right ways of application and the suitable interval between harvesting and pesticide treatment. In most developing countries, farmers have low to moderate levels of knowledge about pesticides (Szpyrka et al. 2015; Armah 2011) and pesticide safety labels (Boobis et al. 2008). Farmers also misuse pesticide and poorly dispose of empty pesticide containers. Poor knowledge in most cases is attributed to lack of training and monitoring in pesticide use and handling (Damalas and Eleftherohorinos 2011). Pesticide users' inability to adhere to stipulated instructions leads to pesticide exposure not only to themselves but to the general public and the environment.

The Zambia Environmental Management Agency (ZEMA) provides for control of pesticide use through the licensing system and ensures that only acceptable pesticides are allowed in the country and found on the Zambian market. However, ZEMA's enforcement capacity is inadequate and cases of non-compliance are rampant (COMACO 2014) resulting in misuse of hazardous pesticides including dichlorvos, while the registration process rarely include testing and verification of the efficacy and hazard characteristics of the pesticide under consideration (COMACO 2014). The purpose of the monitoring program is to ensure that pesticide residues in fruits and vegetables do not exceed maximum residue levels allowed by government, that there is no misuse of pesticides that could result in unexpected residues in food. We set out to investigate dichlorvos residues in rape, cabbage, tomatoes and orange samples in Monze Zambia and verify compliance with standards. We also explored farmers' practices in dealing with monitoring and regulation issues in pesticide use and handling.

\section{Methods}

\section{Study setting}

The research was conducted in Monze district in the southern province of Zambia. Monze town is situated $200 \mathrm{~km}$ south of Lusaka (Zambia's capital city) and $300 \mathrm{~km}$ north of Livingstone. Monze district covers an area of $6687 \mathrm{~km}^{2}$. It lies at $1128.72 \mathrm{~m}$ above sea level, 16 degrees $18 \mathrm{~min}$ south and 26 degrees $28 \mathrm{~min}$ east. Monze district has a projected 2014 population of 206,693 (CSO 2010).

Economically, the district depends on farming, mainly subsistence crop farming (including fruits and vegetable growing) and animal husbandry. Pesticides are largely used to control pests and diseases to improve their market value. Vegetable growers are concentrated along the Magoye River that passes through the district on the east side of Monze town; mainly around Hachaanga, St Mary's and Chikuni areas.

\section{Study design}

Mixed method (convergent parallel) design was used in this study. The quantitative approach used the cross section analytical study design while the narrative study design was used for the qualitative approach. Samples were procured from conveniently sampled fruit and vegetable farmers around Hachaanga and St. Mary's areas of Monze. Prior to sample collection, farmers with fruits and vegetables at maturity stage and had sprayed them with dichlorvos were identified. Key Informant Interviews (KIIs) were conducted with farmers and public authorities to understand pesticide use in Hachaanga and St. Mary's areas of Monze.

\section{Sampling}

A total of 30 samples of cabbage, rape, tomatoes and oranges were procured from nine farmers as per FAO guidelines (Alba 2004); $2 \mathrm{~kg}$ of each vegetable and $1 \mathrm{~kg}$ of oranges per sample were collected 1 day after the application of the pesticide (observed withdraw period). Samples were prepared for residual analysis according to Codex Alimentarius Commission guidelines (FAO/WHO 2014). All the 30 samples were analyzed for residues of dichlorvos using gas chromatography-mass spectrometry (GC-MS).

\section{Sample preparation and analysis}

About $1 \mathrm{~kg}$ of each vegetable and orange sample was thoroughly washed and chopped using a laboratory knife. This was blended using a waring laboratory blender 
with a variable speed to form a composite sample. A total of $50 \mathrm{~g}$ was then taken from the composite sample. After milling, a $20 \mathrm{~g}$ sample was placed into a $250 \mathrm{ml}$ beaker, $5.0 \mathrm{~g}$ sodium chloride was added followed by adding dichloromethane, extracted by ultrasonic for $30 \mathrm{~min}$. After that $10 \mathrm{~g}$ anhydrous sodium sulfate was added and stayed for $2 \mathrm{~min}$. The extraction was transferred to a column packed with $4.0 \mathrm{~g}$ anhydrous sodium sulfate and rinsed twice (total of $5 \mathrm{ml}$ ) with dichloromethane, all the eluents were collected and evaporated to near dryness under nitrogen stream at $45{ }^{\circ} \mathrm{C}$, the residue was re-dissolved with about $1 \mathrm{ml}$ Hexane.

A florisil SPE column was conditioned with $6.0 \mathrm{ml}$ mixture of hexane-acetone (4:1) and $5.0 \mathrm{ml}$ hexane, the concentrated extraction was loaded on the top of the cartridge, and followed by eluting with $6.0 \mathrm{ml}$ mixture of hexane-acetone (4:1), the eluent was collected, and evaporated to near dryness under nitrogen stream at $45{ }^{\circ} \mathrm{C}$. The dried extract was then re-dissolved in acetonitrile solvent and final extract of $1 \mathrm{ml}$ injected in the gas-mass spectrometry chromatography. The gas chromatographymass spectrometry from Shimadzu was used for measurement of dichlorvos residues. External standard calibration was used to prepare the calibration curve, using concentrations of $5,6,7,8,9$ and $10 \mu \mathrm{l} / \mathrm{ml}$. The curve type was linear, original not forced; weighted method: None equation was:

$$
\begin{aligned}
& Y=2146.629 x+1151.629 \\
& R \wedge 2=0.9844324 \\
& R=0.9921856
\end{aligned}
$$

The amount of the pesticide in each sample was calculated based on the slope of the standard curve.

\section{Data analysis and management}

Pesticide residue values were reported as measured in $\mathrm{mg} / \mathrm{kg}$ and compared to the codex Alimentarius MRL and the Zambia Food \& Drug Act standards. Those that were found to be above MRLs were regarded to have violated the standards while those at or below the MRLs did not.

Stata version 13IC (StataCorp, College Station, Texas, USA) was used to derive median and interquartile ranges of pesticide residue levels in fruits and vegetable types.

\section{Estimated average daily intake calculation}

The estimated average daily intakes (EADI) were found by multiplying the median residual pesticide concentration $(\mathrm{mg} / \mathrm{kg})$ by the consumption rate $(\mathrm{kg} /$ day). To evaluate the safety of consumers, exposure estimates were assessed and compared to the acceptable daily intake (ADI) established by FAO/WHO (FAO/WHO
2004). Health risk indices were computed using data obtained from Zambia Food consumption and Micronutrient status survey report (Halimatou et al. 2014) as $21.9 \mathrm{~kg} /$ year for vegetables and $54.75 \mathrm{~kg} /$ year for fruits. This was based on assumptions that; everyone consumes vegetables on daily basis as Zambian diet is mainly vegetarian. One hundred percent of the vegetables are consumed after $24 \mathrm{~h}$ (observed withdrawal period) of pesticide application. The estimated hazard indices were calculated by dividing the EADI ( $\mathrm{mg} / \mathrm{kg} /$ day) by the corresponding value of $\mathrm{WHO} / \mathrm{FAO}$ acceptable daily intake (Table 2).

\section{Qualitative study \\ Population and data collection}

Key informants were purposively sampled based on their knowledge on pesticide use, handling and regulation. Identification of farmers was done through agriculture extension officers manning the two study areas. Farmers with fruits and vegetables at maturity stage and had sprayed them with dichlorvos were eligible for KIIs and their produce for residue testing. Other key informants included agriculture extension officers, block extension, senior crop officer, public health department officer (from $\mathrm{MOH}$ ) and ZEMA officer. Apart from one policy maker who was based in Lusaka, all the key informants were Monze residents. All KII were purposively selected as they were viewed to have information on the study subject. Only key informants who consented were interviewed.

Ten farmers and six officers were identified bringing the sample size to 16 . All 16 eligible respondents were approached to participate in the study, but two (one farmer and one health officer from council) refused to consent, and this reduced the sample size to 14 as the two who declined to participate could not be replaced. Key informant interviews (KIIs) were conducted using semi-structured interviews using two different structured guides, one for farmers and another for policy makers or regulators. KIIs were audio recorded with the permission of the participants. Field notes were also taken during KIIs which lasted between 20 and $40 \mathrm{~min}$. Secondary data reviewed included the Zambia Daily mail article by ZEMA which was posted on $15^{\text {th }}$ December, 2015.

Key informant interviews with individual farmers were conducted in the local language (Tonga) and translated to English by the principle investigator who is a native Tonga speaker. Interviews with agriculture, public health and ZEMA officers were done in English. All KIIs were then transcribed and formatted in Microsoft word before importation into Nvivo10 software for the analysis process. Guiding questions focused on farmers' practices on pesticide use and handling, knowledge on pesticide 
use and handling, knowledge on health effects of pesticide residues and issues of training, pesticide regulation and monitoring.

Key Informant Interviews were analyzed using thematic analysis according to the six-stage process of thematic analysis starting with familiarization, generation of initial codes, searching for themes, reviewing themes, defining and naming themes and finishing with the final report (Lawson 2014). Data was transcribed as part of the familiarization stage. Transcribed data was transferred to Nvivo version 10 for arrangement, coding and merging into themes.

Transcripts were carefully and thoroughly read and reread after which initial coding and categorization of themes was done by the principle investigator. Responses that were related through content and context were categorized as themes until no new themes emerged. Codes were categorized according to similar contents and then developed into broader themes.

\section{Results}

Compliance with maximum residue limits (MRL) in sampled fruits and vegetables

Out of 30 samples analyzed, 19 (63.3\%) had pesticide residues while 11 (36.7\%) had none detected (Table 1$)$. Out of the samples that had residues, three had residues above codex Alimentarius Maximum Residue Limits (MRLs) but were within the standards in the Zambia Food and Drug Act. The results also showed that tomato samples were more contaminated (7/9) followed by cabbage samples (6/9). Of the analyzed rape and orange samples half were contaminated with dichlorvos residues (Fig. 1).

When compared to standard recommended daily intake, we found that estimated average daily intake of pesticides were all below the WHO/FAO allowable daily intake (0. 004) and poses no health hazard (Hazard Index $<1$ ) as shown in Table 2.

\section{Findings from qualitative approach}

Demographic characteristics of key informants

A total of 14 key informants were interviewed including nine farmers, four officers from ministry of agriculture and health and one policy maker form ZEMA, Lusaka.
All farmers did not have any alternative employment and two were females.

The major themes that emerged from KII included pesticide use and handling, knowledge of health effects of pesticides, farmers' training on pesticide use and handling and pesticide regulation and monitoring. The major drivers of pesticide residues in fruits and vegetables were lack of training of farmers in pesticide use and handling and lack of pesticide regulation and monitoring at grass root level. These lead to malpractices by the majority farmers as shown in Fig. 2. The details are as presented in subsequent sections.

\section{Pesticide use and handling}

Use of pesticides by fruit and vegetable growers around Hachaanga and St Mary's is common with almost every farmer depending on pesticides for pest control. All respondents confirmed using a number of chemicals in their fruits and vegetables. Doom and Phoskil (trade names for Dichlorvos and monocrotophose respectively) were reported among the frequently used chemicals as stated by Respondent 3 (male) from St Mary's:

"It is true, we use pesticides normally phoskil and doom, vilatel and so on. They are too numerous to mention. But normally we use phoskil and doom" (Male respondent 3-St Mary's).

The frequency of spraying reported ranged from every seven (7) days to fortnightly depending on the pesticide type and only one farmer reported spraying her oranges every three (3) months.

“...... So I make sure that I spray every week if I am on time. But when I see that the tomatoes are almost ready that is when I start spraying after every two weeks" (Male Respondent 2-Hachaanga).

The waiting period observed for Doom (dichlorvos) differed widely amongst the vegetable growers. The majority of the farmers were observing just 1 day, while a few observes 3 or 7 days.

Table 1 Pesticide residue levels in sampled fruits and vegetables collected from Hachaanga and St Mary's

\begin{tabular}{|c|c|c|c|c|}
\hline \multirow[t]{2}{*}{ Vegetable type } & \multirow{2}{*}{$\begin{array}{l}\text { Number of samples } \\
\text { without residues }\end{array}$} & \multicolumn{2}{|c|}{ Number of samples with residues } & \multirow{2}{*}{$\begin{array}{l}\text { Median/IQR in mg/kg } \\
\text { body weight/day }\end{array}$} \\
\hline & & $\begin{array}{l}\text { Less } 0.1 \mathrm{mg} / \mathrm{kg} \\
(.006-.060)\end{array}$ & Above $0.1 \mathrm{mg} / \mathrm{kg}$ & \\
\hline Cabbage & 3 & 5 & 1 & $0.04(0-0.04)$ \\
\hline Tomato & 2 & 6 & 1 & $0.006(0-0.04)$ \\
\hline Rape & 3 & 3 & 0 & $0.02(0-0.04)$ \\
\hline Oranges & 3 & 2 & 1 & $0.02(0-0.07)$ \\
\hline Totals & 11 & 16 & 3 & \\
\hline
\end{tabular}




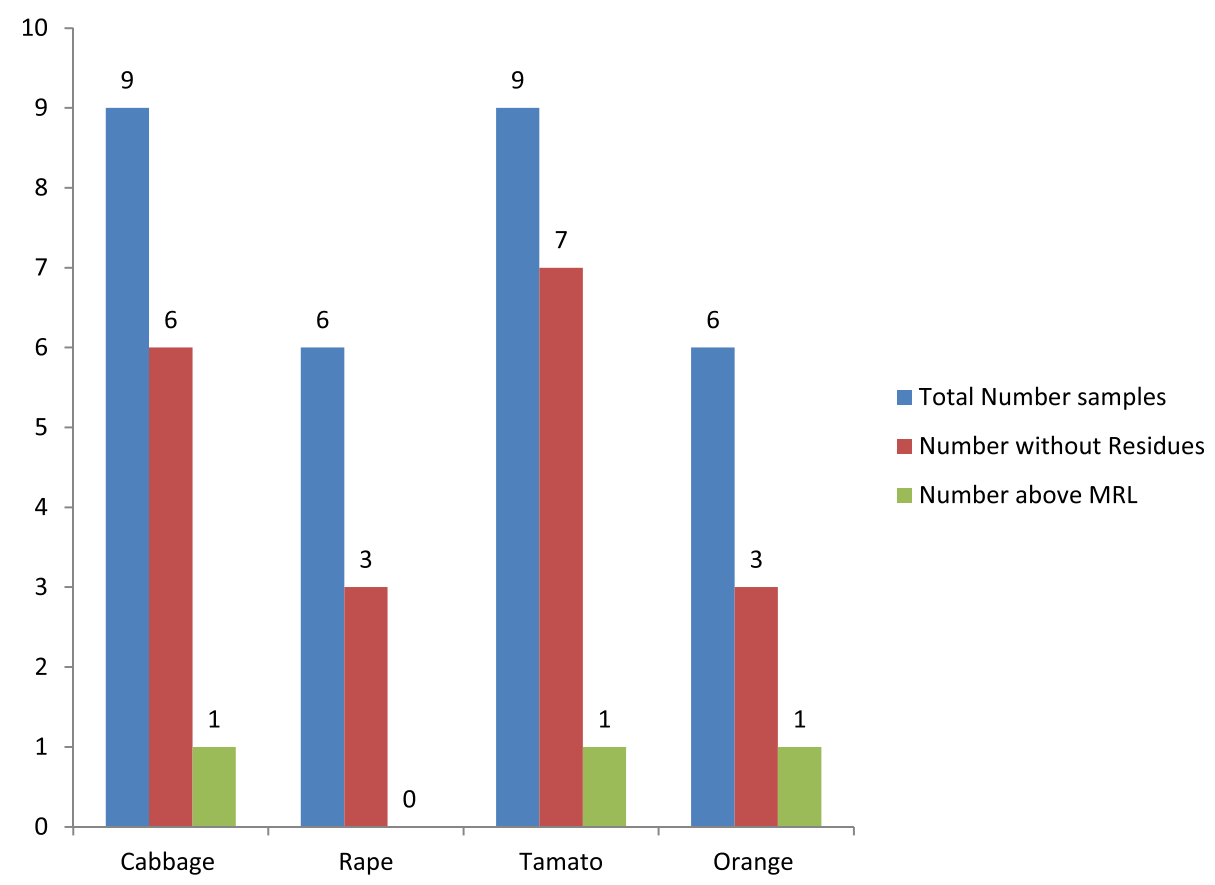

Fig. 1 Pesticide residue levels compliancy with standards per sample type

"According to the knowledge I got from GTZ, in the rainy season you can wait for 3 days only, because vegetables are watered by the rains in addition, there is plenty of water so the chemical becomes inactive quite fast. But in the dry season water is scarce and so vegetables are not adequately watered, therefore, you should wait for full 7 days"

(Male Respondent 2 St Mary's).

Most of the respondents reported following label instructions on the dosage and were aware of the pros and cons of not following label instructions:

"These instructions are followed ... If as a farmer you do not follow the instruction then the health of people is put at stake. So, we as farmers, we should follow these instructions"

(Male Respondent 2-Hachaanga).

Pesticide containers were mainly in form of plastic containers or plastic packs. Disposal methods that came out clearly were burying, disposal in pit latrine and burning. However, field observations showed that most of the farmers left pesticide empty containers in their fields buried with a thin layer of earth or glass (Fig. 3), contrary to ZEMA recommendations that pesticide containers should be buried in deep pits or burned.

One respondent from Hachaanga cited such careless behavior as a cause of poisoning and danger to children who follow their parents to the vegetable fields:

"... Yes because others just throw the empty tins anyhow. They do not bury them like I indicated, they just throw them away. Children then pick them and get poisoned. You see this child madam, she almost died, that one (pointing at her granddaughter who was watering vegetables)... She picked a tin, started kujikilila (role-playing cooking) and eat the vegetables they had cooked in the tin and got poisoned".

(Female Respondent 1-Hachaanga)

Table 2 Health risk assessment based on average daily intake of pesticide residues in fruits and vegetables

\begin{tabular}{lllll}
\hline Vegetable type & $\begin{array}{l}\text { Median value } \\
(\mathrm{mg} / \mathrm{kg})\end{array}$ & $\begin{array}{l}\text { WHO/FAO ADI } \\
(\mathrm{mg} / \mathrm{kg} \text { body weight })\end{array}$ & $\begin{array}{l}\text { EADI } \\
(\mathrm{mg} / \mathrm{kg} \text { body weight })\end{array}$ & $\begin{array}{l}\text { Hazard index } \\
\text { EADI/ADI }\end{array}$ \\
\hline Cabbage & 0.040 & 0.004 & 0.0024 & 0.60 \\
Rape & 0.020 & 0.004 & 0.0012 & 0.30 \\
Tomatoes & 0.006 & 0.004 & 0.00036 & 0.09 \\
Oranges & 0.020 & 0.004 & 0.0030 & 0.75 \\
\hline
\end{tabular}




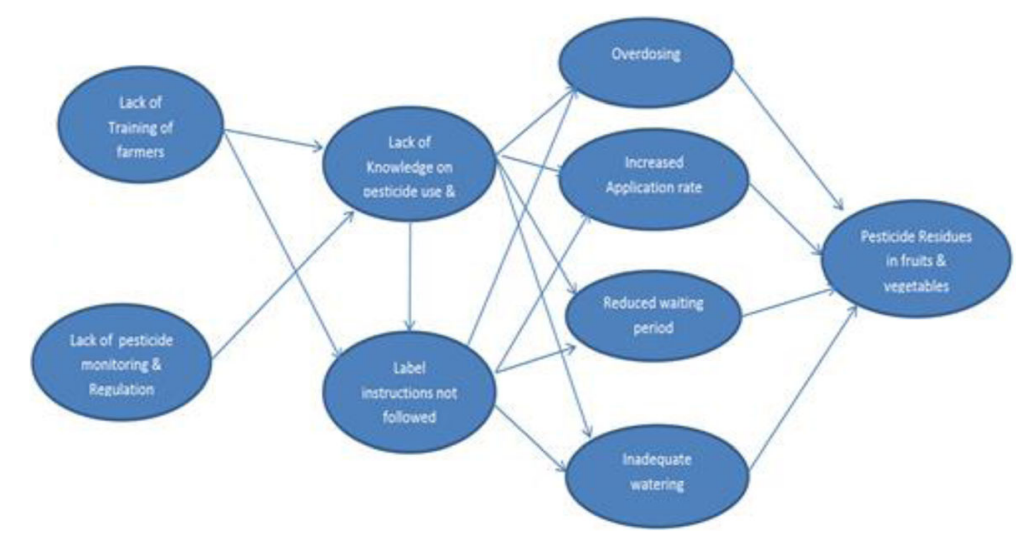

Fig. 2 Causes of pesticide residues; possible associations

\section{Knowledge on pesticide use and handling}

Respondents from Hachaanga and St Mary's had basic information on pesticide use and handling. Most of them acquired this knowledge from reading pesticide labels, from consultations amongst themselves and from agro dealers rather than from being trained or taught by relevant personnel. However much of the information was still limited.

During the time of the research, ZEMA (which is the pesticide regulating agency in the country) was equally concerned about lack of knowledge (which is as a result of lack of formal training) amongst farmers in the country and this is according to the Zambia Daily mail article of $15^{\text {th }}$ December 2015 that we reviewed.

As ZEMA, we are concerned with the lack of knowledge on how to handle, use and dispose of agro-chemicals in the country. We are now working with various institutions to enhance knowledge and understanding on how to use agro-chemicals

(Zambia Daily mail article December 15, 2015).

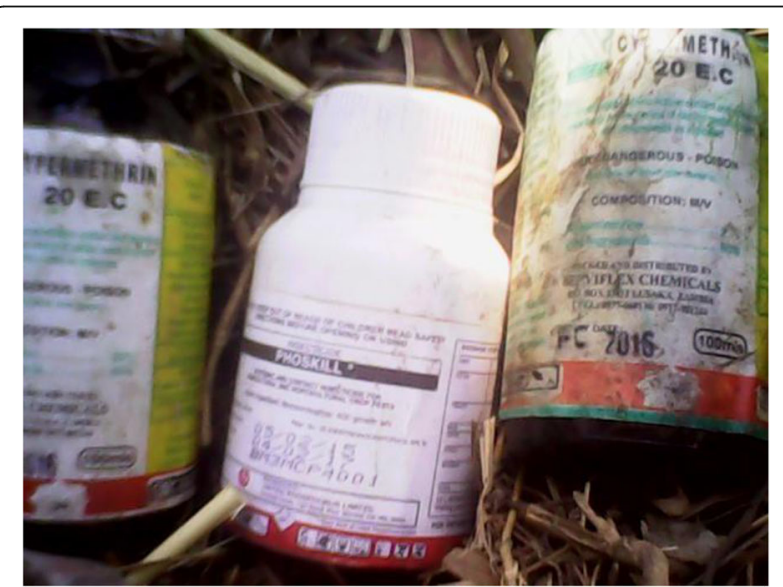

Fig. 3 Pesticide containers in vegetable field

\section{Knowledge on health effects of pesticides}

Most of the respondents knew the health effects of pesticides to humans. A few knew the effects of pesticides on the environment. Stomach pains, diarrhea, eye and skin irritations, chest problems poisoning and cancer were some of the common health effects of pesticides cited. However, most of the respondent fruit and vegetable farmers showed massive ignorance on causes of pesticide residues in fruits and vegetables.

"Yes, immediately after spraying you feel your chest congested, you don't feel good and even itching in the eyes because when you spray, when it is windy, when the wind is moving fast, you can feel it in your eyes as well. Yes, so you feel congestion on your throat, chest and eye irritation as well."

(Female Respondent 4-Hachaanga)

\section{Training of farmers in pesticide use and handling}

Despite agriculture officers confirming training of farmers in the use of pesticides, the majority of the farmers who are the end users of pesticides said they were not trained in pesticide use and handling.

\section{"I have not undergone any major training apart from} having meetings with fellow farmers where we encourage each other and learn from one another. Otherwise I have not gone for any training where I learnt about the use of these chemicals. Otherwise I just depend on my own knowledge and agro-dealers." (Male Respondent 5-St Mary's)

\section{Pesticide regulation and monitoring}

The majority interviewed reported that there was no monitoring amongst farmers on how they use and handle pesticides in their vegetable growing by relevant authorities: 
"As farmers we just go buy these chemicals and come and spray. Like being checked on how we use these chemicals, they don't check on us." (Male Respondent 1St Mary's)

Key informant interviews also revealed inadequacies in regulation and monitoring of pesticide use among farmers. There was also on clear policy as to who is responsible for pesticide residue monitoring in fruits and vegetables. This is what key informant policy makers had to say.

"...that we regulate when something is manufactured, after that, if someone is going to transport, distribute or sale but we do not regulate the point of application. We do not go that far. But we end at distribution, if someone is distributing, then we end there". (Female respondent policy maker, ZEMA)

\section{Discussion}

Assessment of dichlorvos residue levels in locally produced fruits and vegetables in Monze-Zambia revealed that although more than half of the collected samples were contaminated, levels were all below the food and drug act (Zambia) standards. However $30 \%$ of the contaminated samples violated the codex Alimentarius standards. The estimated daily intakes were also found to be below what is allowable in all fruit and vegetable samples. However, hazard indices for cabbage and oranges were close to the value one. Root cause analysis for the qualitative revealed lack of training of farmers in pesticide use and handling and lack of pesticide monitoring and regulation among farmers as major drivers of pesticide residues in fruits and vegetables. Farmers reported great variation in pesticide use and handling, observation of reduced waiting periods, knowledge and training on pesticide use. Also, monitoring and regulation of pesticide use among farmers was very limited.

The presence of dichlorvos residues in fruits and vegetables, a pesticide banned and/restricted in other countries, is a serious concern and threatens the health of consumers. Violation of codex MRLs in some samples is an indication of deviation from good agriculture practices, which is corroborated by the KIIs. These findings are contrary to results of a study done in Lusaka, Zambia which showed that the average levels of dichlorvos were significantly above the maximum accepted limit as set by Zambian Food and Drugs Act on vegetables (Sinyangwe and Sijumbila 2016). High pesticide concentrations in fruits and vegetables may be caused by a number of factors including differences in pesticide application and other habits such as spraying close to maturity stage due to pest pressure. Other countries that have reported residues of banned or restricted pesticides in analyzed vegetable samples include Ghana, Egypt and
Poland (Darko and Akoto 2008; Szpyrka et al. 2015; Farag et al. 2011).

Several studies have shown that even low level exposure to dichlorvos can cause neuropsychiatric conditions (Ross et al. 2010). Moreover, scientists cannot say for sure that there is ever a "safe level" of pesticide residues in food because many chemical messengers in our bodies function at precisely minute quantities of ppm or even ppb (Boobis et al. 2008). The presence of these pesticides therefore calls for vigilance in monitoring pesticide residue levels in fruits and vegetables.

The use dichlorvos in fruits and vegetables as practiced by farmers around Hachaanga and St Mary's poses a health risk to consumers as pesticides can accumulate on vegetable leaf surfaces and may lead to higher pesticide residues. This was similar to findings of studies done in Northern Malawi and Eastern Zambia and Nigeria were respondents reported using pesticides that are hazardous (class1) according to WHO classification. By this practice the farmers are also continually being exposed to pesticides and this can lead to an array of health effects depending on the pesticide's toxicity and the dose take in by the body (Coble et al. 2005). The rate of application by most of the farmers was on weekly basis whether or not pests are present. Despite such an increased rate of application, the majority of the farmers observed reduced waiting periods; one (1) day after pesticide (dichlorvos) application. These variations on the waiting period observed by the farmers indicate noncompliancy to label instructions and lack of training in pesticide use. This was despite the fact that the majority of these farmers knew the health effects of pesticides and confirmed experiencing common effects like skin and eye irritation, abdominal pains and diarrhea.

The results also clearly indicated lack of knowledge among farmers in pesticide use and handling. This was attributed to lack of training and monitoring by agriculture officers and poor attitude of vegetable growers. The findings are in agreement with findings of a study done in Ethiopia that demonstrated lack of knowledge among small scale farmers as one of the contributing factors of pesticide residues (Mekonnen and Agonafir 2002). The studies suggested poor attitude and behavior of the vegetable producers, lack of awareness in the pesticide management coupled with weakness in the agriculture extension services as drivers of poor handling and use of pesticides. Unlike a study in Ghana where half the vegetable farmers had received training on safe handling and application of pesticide (Bempah et al. 2012), majority of farmers interviewed were not trained in pesticide use and handling. The relatively high number of farmers without formal training and knowledge in pesticide use is an important source of concern as pesticides are hazardous chemicals that require to be handled with 
caution. The commonest way of disposing of empty pesticide containers cited among the respondent farmers was by burying in dip holes and pit-latrine or by burning. However the finding of the study was that the majority of the respondent farmers left pesticide containers in their vegetable fields buried with either a thin layer of glass or earth. This practice is a serious threat to human health and the environment as improper disposal of empty pesticide containers can lead to contamination of soil, ground and surface water, causing serious problems for the pesticide user, consumers and the environments.

The agriculture sector in Zambia has continued to use restricted/banned pesticide such as dichlorvos without rigorous monitoring and regulation system. In advanced countries, strict pesticide regulation and enforcement mechanism are put in place to ensure their safe use and handling and high standards are set to ensure safety of consumers (Bempah et al. 2012). However, this is not the case in developing countries including Zambia. In Zambia, of serious concern is the fact that a list of banned or strictly restricted pesticides is non-existence (COMACO 2014).

Regulatory agencies also face enormous challenges including poor funding, lack of transport and poor policies that prioritize curative over preventive programs. As a result routine pesticide residue monitoring in fruits and vegetables is not done. The Zambia Food and Drug Act standards for dichlorvos residues in fruits and vegetables are also low $(0.5 \mathrm{ppm}=0.5 \mathrm{mg} / \mathrm{kg})$ compared to international standards $(0.1 \mathrm{mg} / \mathrm{kg}$ by Codex and $0.2 \mathrm{mg} / \mathrm{kg}$ by European Union). Setting low standards for banned and/ restricted pesticides in developed countries create problems when evaluating potential human risk. Ultimately high amounts of these hazardous chemicals are allowed in the food chain at the expense of everyone's health. A literature review on pattern and epidemiology of poisoning in East African region reported organphosphorus poisoning as one of the key causes of nontraumatic coma in Zambia (Tagwireyi et al. 2016).

\section{Study limitations}

In spite of the fact that a wide range of pesticides are currently used to control pests in fruits and vegetables, this study only focused on analysis for the presence of dichlorvos. The qualitative study however covered practices on the use of both dichlorvos and monocrotophos. Also, the study did not attempt to collect all fruit and vegetable samples from all suppliers in town. As such, results of this study will only apply to these two types of pesticides and will not be generalized to all fruit and vegetable suppliers in Monze. Therefore, these results are an underestimation of exposure to pesticides by consumers. There is need to conduct a comprehensive study to cover multiple pesticides and all fruits and vegetable types in order to wider overview of contamination levels.

\section{Conclusion}

It can be concluded that, pesticide residues in fruits and vegetables from Hachaanga and St Mary's were within locally acceptable standards. However, the combination of factors including increased application rate, reduced waiting period, limited knowledge and training of the majority of farmers and absence of monitoring services regarding residual levels of pesticides in fruits and vegetables seriously threaten consumers. Therefore, there is need to strengthen pesticide regulation and monitoring by extension of the regulation to include pesticide end users. Training of farmers in pesticide use and handling should also be greatly improved to increase awareness and encourage right practice for the safe use of pesticides. Development of a list of banned pesticides by ZEMA which should include dichlorvos to stop its importation in the country is justified according to the findings of this study. Furthermore, revision of the Zambia Food and Drugs Act in regards to standards of pesticide residues in fruits and vegetables is necessary to meet international standards.

\section{Abbreviations \\ CSO: Central Statistics Office; EPA: Environmental Protection Act; FAO: Food and Agriculture Organization; FDA: Food and Drugs Act; GAP: Good agriculture practices; Kll: Key Informant Interview; MAL: Ministry of Agriculture and Livestock; $\mathrm{MOH}$ : Ministry of Health; MRL: Maximum residue levels; UNZA: University of Zambia; WHO: World Health Organization; ZEMA: Zambia Environmental Management Agency}

\section{Acknowledgments}

We would like to thank and appreciate our Colleagues at Ministry of Agriculture offices in Monze for granting us permission to carry out the research among their farmers. We also acknowledge the indispensable input of professor Michelo (Head of Department of Public Health, University of Zambia), Dr. Anjali Sharma, Dr. Roma Chilengi.M.D. and Dr. Wilbroad Mutale (CIDRZ) in the perfection of this work. We are greatly indebted to you all. We also would like to thank Mr. Mwanza Bisalom for his input in qualitative data analysis.

Funding

No specific funding was received for this research.

\section{Availability of data and materials}

The datasets supporting the conclusion of this article are included within the article and its additional files.

\section{Ethics approval and consent to participate}

This research involved procurement of vegetable and fruit samples from local farmers in town. Ethical issues leading to loss of market by individual farmers could have arisen. Procurement was only done from farmers who consented. Individual farmers were identified with serial numbers and not names for confidentiality sake. Permission to carry out the research was sought from Excellence in Research Ethics and Science (ERES) and Ministry of Agriculture and Livestock (MAL). The permission letter from MAL was then presented to agriculture Extension officers operating in the different areas. Then, research objectives were explained fully to individual farmers.

\section{Authors' contributions}

The research was originated by MM for the award of Master of Public Health with support from NSM, AM and CJ. With the technical support and guidance of the other co-authors, MM conducted sample and data collection. NSM, AM and CJ were all my supervisors and together we worked out the research idea. They also provided technical support in data analysis and interpretation, and draft of this manuscript. All authors have read and agreed to the final version of this manuscript for publication. 


\section{Consent for publication}

Not applicable.

\section{Competing interests}

The authors declare that they have no competing interests.

\section{Publisher's Note}

Springer Nature remains neutral with regard to jurisdictional claims in published maps and institutional affiliations.

\section{Author details}

${ }^{1}$ Environmental Health Department, Monze District Medical Office, P.O. Box 66144, Monze, Zambia. ${ }^{2}$ School of Medicine Department of Public Health, Environmental Health Unit, University of Zambia, P.O Box 50110, Ridgeway, Lusaka, Zambia. ${ }^{3}$ School of Medicine Department of Epidemiology and Biostatistics Unit, University of Zambia, P.O Box 50110, Ridgeway, Lusaka, Zambia.

Received: 26 April 2017 Accepted: 25 June 2017

Published online: 12 July 2017

\section{References}

Alba AF. Chromatographic-mass spectrometric food analysis for trace determination of pesticide residues, Spain. vol. 43. Almeria: Elsevier; 2004. Armah FA. Assessment of pesticide residues in vegetables at the farm gate: Cabbage (Brassica oleracea) cultivation in Cape Coast, Ghana. Res J Environ Toxicol. 2011;5(3):180.

Bempah CK, Asomaning J, Boateng J. Market basket survey for some pesticides residues in fruits and vegetables from Ghana. J Microbiol Biotechnol Food Sci. 2012:2(3):850

Boland J, Koomen I, JvL d J, Oudejans J. AD29E Pesticides: compounds, use and hazards. Netherland. Agromisa Foundation; 2004.

Boobis AR, Ossendorp BC, Banasiak U, Hamey PY, Sebestyen I, Moretto A. Cumulative risk assessment of pesticide residues in food. Toxicol Lett. 2008; 180(2):137-50.

Bwalya SM. Sound Management of the Chemicals in Zambia. A cost benefit analysis of the Agriculture Chemical use in the Kafue basin. 2010

Coble J, Arbuckle T, Lee W, Alavanja M, Dosemeci M. The validation of a pesticide exposure algorithm using biological monitoring results. J Occup Environ Hyg. 2005;2(3):194-201.

COMACO. Community Markets for the COMACO landscape management project P144254 : Pest management plan (PMP), November 2014. Proc Natl Acad Sci. 2014;29:8-33

CSO. 2010 Zambia Census of Population and Housing, Preliminary report Lusaka: Central Statistics Office, Republic of Zambia; 2010.

Damalas CA, Eleftherohorinos IG. Pesticide exposure, safety issues, and risk assessment indicators. Int J Environ Res Public Health. 2011:8(5):1402-19.

Darko G, Akoto O. Dietary intake of organophosphorus pesticide residues through vegetables from Kumasi, Ghana. Food Chem Toxicol. 2008:46(12): 3703-6.

FAO/WHO. Joint FAO/WHO Expert Committee on Food Additives. 2004

FAO/WHO. Food Standards Programme. Geneva: Codex Alimentarius Commission; 2014. 14-18 July 2014

Farag R, Latif A, Abd El-Gawad A, Dogheim S. Monitoring of pesticide residues in some Egyptian herbs, fruits and vegetables. Int Food Res J. 2011;18(2):659-67.

Greish S, Ismail SM, Mosleh Y, Loutfy N, Dessouki AA, Ahmed MT. Human Risk Assessment of Profenofos: A Case Study in Ismailia, Egypt. Polycycl Aromat Compd. 2011;31(1):28-47.

Halimatou A, Kohler L, Taren D, Mofu M, Chileshe J, Kalungwana N. Zambia food consumption and micronutrient status survey report. Lusaka: National Food and Nutrition Commission DRAFT; 2014.

Lawson A (2014) UWE Research Repository annual report Sept 2013-Aug 2014.

Mekonnen Y, Agonafir T. Pesticide sprayers' knowledge, attitude and practice of pesticide use on agricultural farms of Ethiopia. Occup Med. 2002;52(6):311-5.

Mowry JB, Spyker DA, Brooks DE, McMillan N, Schauben JL. 2014 annual report of the american association of poison control centers' national poison data system (npds): 32nd annual report. Clin Toxicol. 2015:53(10):962-1147.

Ntow WJ, Gijzen HJ, Kelderman P, Drechsel P. Farmer perceptions and pesticide use practices in vegetable production in Ghana. Pest Manag Sci. 2006;62(4): 356-65.
PAN G. Pesticides and health hazards facts and figures. Bochum: Pestizide und Gesundheitsgefahren: Daten und Fakten; 2012

Ross SJM, Brewin CR, Curran HV, Furlong CE, Abraham-Smith KM, Harrison V. Neuropsychological and psychiatric functioning in sheep farmers exposed to low levels of organophosphate pesticides. Neurotoxicol Teratol. 2010;32(4):452-9.

Sinyangwe DM, Sijumbila G. Determination of dichlorvos residues levels in vegetables sold in Lusaka Zambia. Pan Afr Med J. 2016;23(1):1-18.

Szpyrka E, Kurdziel A, Matyaszek A, Podbielska M, Rupar J, Słowik-Borowiec M. Evaluation of pesticide residues in fruits and vegetables from the region of south-eastern Poland. Food Control. 2015;48:137-42.

Tagwireyi D, Chingombe P, Khoza S, Maredza M. Pattern and epidemiology of poisoning in the East African region: a literature review. J Toxicol. 2016:2016:1-26.

Wang J, Chow W, Leung D. Applications of LC/ESI-MS/MS and UHPLC QqTOF MS for the determination of 148 pesticides in fruits and vegetables. Anal Bioanal Chem. 2010;396(4):1513-38.

\section{Submit your manuscript to a SpringerOpen ${ }^{\circ}$ journal and benefit from:}

- Convenient online submission

- Rigorous peer review

- Open access: articles freely available online

- High visibility within the field

- Retaining the copyright to your article

Submit your next manuscript at $>$ springeropen.com 